\title{
Effects of Solute Trapping on Solidification Path in Ta-rich Ta-Al-Fe Ternary Alloys under Rapid Freezing
}

\author{
N. D’Souza ${ }^{1}$, L. M. Feitosa ${ }^{2}$, G. D. West ${ }^{3}$, N. G. Jones ${ }^{4}$, H. B. Dong ${ }^{2 *}$ \\ ${ }^{1}$ Rolls-Royce plc, PO. Box 31, Derby, DE24 8BJ, UK \\ ${ }^{2}$ Department of Engineering, University of Leicester, Leicester, LE1 7RH, UK \\ ${ }^{3}$ Warwick Manufacturing Group, University of Warwick, Coventry, CV4 7AL, UK \\ ${ }^{4}$ Department of Materials Science and Metallurgy, University of Cambridge, Cambridge CB3 OFS,UK
}

\begin{abstract}
The solidification sequence of Ta-rich Ta-Al-Fe alloys was examined under rapid freezing processes, arc melting and splat cooling techniques. It is found that loss of interfacial equilibrium results in an extended solubility of $\mathrm{Al}$ (up to 15 at. \%) and a lower Fe content in primarily Ta phase (A2) in arc melted samples. Trapping of Al in the primary phase leads to a deviation of the solidification path from equilibrium prediction. When $\mathrm{Al}$ content is less than 10 at. \% $\mathrm{Al}$ and $\mathrm{Fe}$ content is less than 4 at. \% in the primary phase, the peritectic reaction, $\mathrm{L}+\mathrm{A} 2 \rightarrow \sigma$, is suppressed and instead the eutectic reaction, $\mathrm{L} \rightarrow \mathrm{A} 2+\mu$ takes place following primary freezing. It is also found that under splat cooling conditions extended solute solubility occurs in $\mu$ phase formed via a eutectic reaction.
\end{abstract}

\section{Introduction}

The natural choice of material for the turbine in aero engine applications are Ni-base superalloys owing to their excellent combination of strength, ductility and high temperature oxidation properties [1-4]. However, stringent requirements for decreased emissions and higher efficiency necessitate a stepincrease in turbine entry temperature. This requirement has driven the need for research into other alloy systems that might offer a higher operating temperature capability, as an alternative option to Ni-base superalloys.

Some of the key requirements for such alternate alloy systems are lower density, superior creep strength and good environmental resistance, which might come with some compromise to ductility. The remarkable high temperature strength of Ni-base superalloys is derived from the presence of ordered (super-lattice) precipitates, $\gamma^{\prime}$ dispersed in a ductile $\gamma$ matrix and forming a coherent interface [5]. It had been demonstrated that alloys with super-lattice precipitates exhibited superior deformation and creep behaviour compared to either of the constituent phases and which had formed the basis for the design of these alloys $[6,7]$. Keeping this in mind in the investigation of ternary systems as alternate candidate materials, one such possible system is the RM-X-Al system. Here, RM refers to a refractory metal. This choice is based on the following rationale; 
- $\quad \mathrm{RM}$ is required for strength, typically solid-solution hardening and

- $\mathrm{Al}$ ensures the formation of a slow growing and dense oxide.

Examples of such systems investigated in the past were $\mathrm{Nb}-\mathrm{Ru}-\mathrm{Al}$ and $\mathrm{Nb}-\mathrm{Pd}-\mathrm{Al}$, where it was shown that $\mathrm{A} 2+\mathrm{B} 2$ or $\mathrm{A} 2+\mathrm{L} 2{ }_{1}$ phase mixtures exist, where $\mathrm{A} 2$ is bcc-disordered matrix, while the precipitates are super-lattice, i.e. B2, $\mathrm{CsCl}$ structure or $\mathrm{L} 2$, the Heusler phase [8, 9]. Another possible ternary system is the Ta-Al-Fe system, where the focus is on the Ta-rich corner. The principal phases reported were $\mathrm{A} 2, \sigma\left(\mathrm{Ta}_{2} \mathrm{Al}\right)$, which is tetragonal $\left(\mathrm{D} 8_{\mathrm{b}}\right)$ and $\mu\left(\mathrm{TaFe}\right.$ or $\left.\mathrm{Ta}_{6} \mathrm{Fe}_{7}\right)$, which is rhombohedral [10]. The AlFe-Ta ternary system has been recently assessed by Ghosh [11], who has substantially improved on previously reported data $[12,13]$. However, the main composition range studied was limited to the Allean and Ta-lean regions; $<35$ at. $\% \mathrm{Al}$ and $<50$ at. \% Ta respectively. Also, partial isothermal sections at $\mathrm{T}=1273 \mathrm{~K}$ have been studied that report on the stability of $\mu$ and $\lambda$ (C14 Laves) phases that were observed in the binary systems for these ranges in composition [14]. More recently detailed thermodynamic modelling as well as experimental analysis has been carried out and in addition to the isothermal sections, the liquidus and solidus projections have also been determined [10]. Moreover, some compositions in the Ta-rich corner have been considered, where the primary freezing of $\sigma, \mu$ and A2 (Ta) was observed.

A possible processing route for large-scale manufacture of components made from these alloys is via the solidification route. Therefore, it is important to understand the solidification sequence in these alloys, which in turn will dictate the heat treatment required thereafter to obtain the desired microstructure. Under normal conditions of solidification even though diffusion in the solid is limited, it is still appropriate to assume that equilibrium conditions exist at the solid/liquid interface [15]. Notwithstanding this, in a ternary system where an "added degree of freedom" exists during primary freezing and depending on the diffusion in the solid, the relative amounts of phases present depends on the path followed by the liquid composition on the liquidus surface [16]. Also, since these alloys are high melting and significant superheat exists, a wide range in cooling rates are likely to be encountered during freezing. In such cases, it has been observed that under conditions of rapid solidification, extended solute solubility occurs and accompanied by significant deviations from the expected freezing sequence [17 - 19].

Consequently, it is important to derive the solidification path in these alloys, especially under rapid freezing conditions which occurs in commonly used processing routes such as arc melting and splat cooling techniques. The aim of this article is to systematically study the freezing path of a series of alloys in the Ta-rich corner of the phase diagram, which encompass the different primary phases, the uni-variant eutectic and peritectic reaction and the invariant Class II invariant reaction. The different compositions investigated in this study are plotted in Fig. 1(a) - liquidus projection and Fig. 1(b) solidus projection and other details are listed in Table 1. 


\section{Experimental}

To derive the solidification path in the alloys under rapid freezing conditions, samples were produced using the following two methods:

(i) Suspended Droplet Alloying (SDA) utilises a laser beam to melt elemental wire feedstock in order to produce a bulk alloy material sample. Compositionally different samples can be synthesised by varying the ratio of wire feed rates.

(ii) Arc melting, which involved melting of elemental powders on a cooled $\mathrm{Cu}$ hearth.

In (i), compositionally different samples were synthesised by varying the ratio of wire feed rates. An alloy button is built by depositing a number of alloy droplets onto a substrate whilst maintaining a melt pool on the top of the sample. Al, Co and Ta wires are fed into the beam path and subsequently melt. The melting process initiates the formation of a droplet on the tip of each wire and eventually the droplet "pinches off". As the droplet comes into contact with the copper substrate it spreads and is quenched rapidly to form a "splat". Cooling rates for these splats are estimated to be in the region of $10^{3} \mathrm{~K} \mathrm{~s}^{-1}$. The laser beam was then fired in continuous wave mode and the wire feeders were activated. The bespoke alloy synthesis system utilised was manufactured by Renishaw plc. and was fitted with a $1000 \mathrm{~W}$ fibre laser with a wavelength of $630-680 \mathrm{~nm}$. The beam was introduced into the atmosphere-controlled chamber through a fused silica window. Within this atmosphere-controlled chamber oxygen levels were kept at $10 \mathrm{ppm}$ during processing with an additional flow of shielding gas from the copper nozzle at a rate of $3 \mathrm{~L} / \mathrm{min}$ over the alloy material during synthesis and cooling.

In (ii), small ingots of each alloy, weighing $\sim 40 \mathrm{~g}$, were cast via arc melting on a water-cooled hearth in an evacuated and argon backfilled atmosphere. Elemental metals, with purity $\geq 99.9 \%$, were used as the feedstock and to minimise the loss of $\mathrm{Al}$ during the melting process, the alloys were fabricated in a two-step procedure. A binary alloy was created from the refractory and transition metals, which was subsequently melted with pure Al to create the final ingot. To increase the homogeneity of both the binary and ternary alloys, at least two re-melting operations were used at each stage in between which, the ingots were physically inverted on the hearth.

All scanning electron microscopy (SEM) was performed using a dual beam (FEI Nova 600 Nanolab), Focused Ion Beam (FIB)/ Field Emission Gun Scanning Electron Microscope (FEG-SEM). Backscattered electron images (BEI) were collected using a retractable solid-state back-scatter detector using high $(20 \mathrm{kV})$ electron beam accelerating voltages for enhanced compositional contrast. Chemical analysis was undertaken in this system at $20 \mathrm{kV}$ using Energy Dispersive Spectroscopy (EDS) using an Octane super $60 \mathrm{~mm}^{2}$ Silicon Drift Detector (SDD) from EDAX. The dual beam system was also used to prepare site specific TEM samples using an in-situ lift-out procedure. This involves depositing $\mathrm{Pt}$ using the gas injection system (GIS) over the $20 \mu \mathrm{m}$ long area of interest, and milling "stair-case" 
trenches on either side. The TEM sample was extracted using an omniprobe micromanipulator and was attached to a $\mathrm{Cu}$ grid. Great care was taken when final thinning to achieve samples that all had similar and uniform thickness. STEM analysis was performed in a FEI Tecnai F20 operating at $200 \mathrm{kV}$. The system is equipped with an Oxford instruments XMAXN 80 TLE windowless SDD EDS detector. Images were collected with a bright field (BF) and High Angular Annular Dark Field (HAADF) detectors in STEM. EDS spectrum maps were collected using Aztec software to assess sample compositional homogeneity. From these maps regions for collecting comparative spectra were defined and these were collected for $20 \mathrm{~s}$ live time.

Table 1: List of samples, elemental composition, condition and observed phases in the microstructure

\begin{tabular}{|c|c|c|c|c|c|c|}
\hline $\begin{array}{c}\text { Sample } \\
\text { ID }\end{array}$ & \multicolumn{2}{|c|}{ Composition (atom \%) } & $\begin{array}{c}\text { Method of } \\
\text { Manufacture }\end{array}$ & $\begin{array}{c}\text { Equilibrium } \\
\text { Phases }\end{array}$ & $\begin{array}{c}\text { Observed Phases } \\
\text { (Experimentally) }\end{array}$ \\
\hline & Ta & Al & Fe & & & \\
\hline S1 & 86.8 & 7.3 & 5.9 & Arc Melting & $\mathrm{A} 2+\sigma$ & $\mathrm{A} 2+\mu$ \\
\hline S2 & 80.2 & 9.8 & 10.0 & Arc Melting & $\mathrm{A} 2+\sigma$ & $\mathrm{A} 2+\mu$ \\
\hline S3 & 78.1 & 10.2 & 11.7 & Arc Melting & $\mathrm{A} 2+\sigma+\mu$ & $\mathrm{A} 2+\mu$ \\
\hline S4 & 75.0 & 17.4 & 7.6 & Arc Melting & $\sigma$ & $\mathrm{A} 2+\sigma+\mu$ \\
\hline S5 & 81.6 & 11.2 & 7.2 & Splat & $\mathrm{A} 2+\sigma$ & $\mathrm{A} 2+\mu$ \\
\hline S6 & 80.5 & 6.9 & 12.6 & Splat & $\mathrm{A} 2+\sigma$ & $\mathrm{A} 2+\mu$ \\
\hline
\end{tabular}

\section{Results}

$\mathrm{S} 1$ and $\mathrm{S} 2$ are both expected to undergo the peritectic reaction, $\mathrm{L} \rightarrow \mathrm{A} 2$ and $\mathrm{L}+\mathrm{A} 2 \rightarrow \sigma$ (liquid consumed), while $\mathrm{S} 3$ is expected to additionally undergo the 4-phase invariant reaction, $\mathrm{L} \rightarrow \mathrm{A} 2, \mathrm{~L}+$ $\mathrm{A} 2 \rightarrow \sigma, \mathrm{L}+\sigma \rightarrow \mathrm{A} 2+\mu$, following from the liquidus and solidus projections in Figs. 1(a) and 1(b) respectively. The low and high magnification back-scattered electron images (BEI's) in Figs. 2(a), 2(b) refer to S1, Figs. 3(a), 3(b) refer to S2 and Figs. 4(a), 4(b) refer to S3 respectively. The solid composition in the different phases is plotted in the liquidus and solidus projection in Fig. 2(c) and Fig. 2(d), and also included are the positions of the phase boundaries at lower temperature in the case of S1 and likewise for S2 in Fig. 3(c) and Fig. 3(d), and for S3 in Fig. 4(c) and Fig. 4(d). The following observations can be made;

- S1: The primary phase is dendritic and the inter-dendritic regions are sporadic and have an acicular morphology. The composition measured at a number of locations across the primary 
dendrite phase is (in at. \%); $\mathrm{Ta}=89.4 \pm 1.29, \mathrm{Al}=6.8 \pm 0.46, \mathrm{Fe}=3.8 \pm 0.83$ and corresponds to A2. The composition measured at a number of locations within the inter-dendritic region is (in at. \%); $\mathrm{Ta}=57.2 \pm 0.27, \mathrm{Al}=13.5 \pm 0.19, \mathrm{Fe}=29.3 \pm 0.08$ and corresponds to $\mu$ phase.

- S2: The primary phase is dendritic. The composition measured at a number of locations across the primary dendrite phase is (in at. \%); $\mathrm{Ta}=88.4 \pm 0.21, \mathrm{Al}=7.5 \pm 0.15, \mathrm{Fe}=4.1 \pm 0.35$ and corresponds to A2. The composition measured at a number of locations within the interdendritic region is (in at. \%); $\mathrm{Ta}=56.0 \pm 0.35, \mathrm{Al}=15.7 \pm 0.15, \mathrm{Fe}=28.3 \pm 0.41$ and corresponds to $\mu$ phase. The composition of $\mu$ phase lies on the single phase boundary in the solidus projection. The morphology of the $\mathrm{A} 2+\mu$ eutectic is primarily divorced, but within $\mu$ phase a lamellar morphology is also observed.

- S3: This is similar to S2. The composition measured at a number of locations across the primary $\mathrm{A} 2$ phase is (in at. \%); $\mathrm{Ta}=87.2 \pm 0.08, \mathrm{Al}=8.5 \pm 0.06, \mathrm{Fe}=4.4 \pm 0.02$. The composition measured at a number of locations within the $\mu$ phase is (in at. \%); $\mathrm{Ta}=56.1 \pm 0.34, \mathrm{Al}=15.5$ $\pm 0.13, \mathrm{Fe}=28.4 \pm 0.22$.

Since $\sigma$ phase is stable with increasing $\mathrm{Al}$ concentration, it is important to examine the composition range beyond which the formation of $\sigma$ phase is not suppressed; unlike in S1, S2 and S3, if at all this is possible. This is investigated by choosing a nominal composition that is progressively enriched in $\mathrm{Al}$ and lower in Fe (e.g. S4), such that the nominal composition is increasingly remote from the A2 - $\mu$ valley in the liquidus projection. The expected solidification sequence in this case is; $\mathrm{L} \rightarrow \mathrm{A} 2$ and $\mathrm{L}+$ A2 $\rightarrow \sigma$ (liquid consumed). The low and high magnification back-scattered electron images (BEI's) are presented in Figs. 5(a), 5(b), while the solid composition in the different phases is plotted in the liquidus and solidus projection in Fig. 5(c) and Fig. 5(d) respectively. The following observations can be made;

- The primary phase is $\mathrm{A} 2$ from the measured composition; $\mathrm{Ta}=81.3 \pm 0.80, \mathrm{Al}=15.0 \pm 0.57$, $\mathrm{Fe}=3.7 \pm 0.53$. Like before, there exists an extended solubility of primarily $\mathrm{Al}$ and to a lesser extent Fe in A2. Primary freezing can therefore be represented as; $\mathrm{L} \rightarrow \mathrm{A} 2$.

- Within the inter-dendritic region there is the distinct formation of a "grey" phase that forms a rim continuously across the dendrite. From the measured composition; $\mathrm{Ta}=70.08 \pm 1.07, \mathrm{Al}=$ $20.2 \pm 1.94, \mathrm{Fe}=9.0 \pm 0.99$, this is $\sigma$ phase. The composition of $\sigma$ phase lies on the boundary of the single phase-field in the solidus projection.

- $\sigma$ phase forms via the peritectic reaction; $\mathrm{L}+\mathrm{A} 2 \rightarrow \sigma$, which commences initially at the solid/liquid interface and can be represented as two reactions; $\mathrm{L} \rightarrow \sigma \& \mathrm{~A} 2 \rightarrow \mathrm{L}[20,21]$. The subsequent peritectic transformation, which is governed by diffusion through the solid, rarely goes to completion and instead primary deposition of $\sigma$ occurs, $\mathrm{L} \rightarrow \sigma$. Here the liquid 
composition leaves the liquidus curve and traverses the $\sigma$-liquidus surface, while the solid composition traverses the solidus surface.

- Solidification terminates with the eutectic reaction, $L \rightarrow \sigma+\mu$, which forms with a divorced morphology. Here the "dark" phase is $\mu$ phase, as determined from the composition measurements; $\mathrm{Ta}=53.2 \pm 1.28, \mathrm{Al}=23.7 \pm 2.73, \mathrm{Fe}=23.3 \pm 1.46$. The composition of $\mu$ phase lies on the boundary of the single phase field in the solidus projection.

From the preceding results (S1, S2, S3 and S4), the following key points can be drawn;

(i) There is an extended solubility of primarily Al and to a lesser extent Fe within the primary dendritic A2 phase, which cannot be accounted for by changes in solute solubility during cooling.

(ii) The solidification path observed is different from that predicted from the liquidus and solidus projections under equilibrium condition. For lower $\mathrm{Al}$ and higher Fe concentrations (S2, S1 and S3), the peritectic reaction $(\mathrm{L}+\mathrm{A} 2 \rightarrow \sigma)$ is suppressed and primary freezing $(\mathrm{L} \rightarrow \mathrm{A} 2)$ is followed by a eutectic reaction $(\mathrm{L} \rightarrow \mathrm{A} 2+\mu)$. The 4-phase invariant reaction in the case of S3 therefore does not occur.

(iii) For higher $\mathrm{Al}$ and lower Fe concentrations (S4), the peritectic reaction is observed. The reaction is then followed by a eutectic reaction.

In the arc melting experiments the thickness of the samples corresponds to the maximum solidification height. This is because the arc was moved along the length of the bar in the transverse direction with the solidification height therefore corresponding to the diameter perpendicular to the length. Such conditions will be accompanied by rapid cooling rates, since the diameter $(\phi)$ is about $10 \mathrm{~mm}$ (akin to the chill zone in castings). Therefore, the implications of the cooling rate with emphasis to (i) and (ii) were investigated using the splat quenching approach resulting in specimens typically $<3 \mathrm{~mm}$ thick. Compositions close to S1, S2 and S3 were prepared and a similar solidification sequence from the liquidus and solidus projections are expected. Figs. 6 and 7 correspond to samples S5 and S6. The following observations can be made;

In both cases, a very fine dendritic microstructure is observed, c.f. Figs. $2-5$, which is consistent with the splat quenching method.

- The primary phase is A2 from the measured composition and there exists an extended solubility of $\mathrm{Al}$ and $\mathrm{Fe}$ in $\mathrm{A} 2$. Primary freezing can therefore be represented as; $\mathrm{L} \rightarrow \mathrm{A} 2$.

$\circ \quad \mathrm{S} 5-\mathrm{Ta}=87.6 \pm 0.87, \mathrm{Al}=6.1 \pm 0.26, \mathrm{Fe}=6.3 \pm 0.80$.

$\circ \quad \mathrm{S} 6-\mathrm{Ta}=88.0 \pm 0.21, \mathrm{Al}=8.4 \pm 0.05, \mathrm{Fe}=3.7 \pm 0.21$ 
- The composition measured at a number of locations within the inter-dendritic region is (in at. $\%) ; \mathrm{Ta}=56.0 \pm 0.35, \mathrm{Al}=15.7 \pm 0.15, \mathrm{Fe}=28.3 \pm 0.41$ and corresponds to $\mu$ phase. Importantly, the composition of $\mu$ phase lies beyond the single phase-field in the solidus projection and cannot be accounted for by changing solubility with decreasing temperature.

$$
\begin{aligned}
& \circ \mathrm{S} 5-\mathrm{Ta}=63.0 \pm 2.45, \mathrm{Al}=8.9 \pm 0.14, \mathrm{Fe}=28.2 \pm 2.33 \\
& \mathrm{~S} 6-\mathrm{Ta}=59.0 \pm 0.07, \mathrm{Al}=18.2 \pm 0.49, \mathrm{Fe}=22.9 \pm 0.57 .
\end{aligned}
$$

- The morphology of the A2 $+\mu$ eutectic is divorced.

It can be unequivocally concluded that with increasing cooling rate, there is also extended solubility of primarily Ta in $\mu$ phase corresponding to the eutectic reaction.

\section{Discussion}

There are two main aspects that required to be considered;

- Following primary freezing of A2 $(\mathrm{Ta})$, the suppression of the peritectic reaction $(\mathrm{L}+\mathrm{A} 2 \rightarrow \sigma)$ for lower $\mathrm{A}$ l concentration and instead replaced by the eutectic reaction $(\mathrm{L} \rightarrow \mathrm{A} 2+\mu)$.

- The reasons and implications for the extended solute of primarily $\mathrm{Al}$ and to a lesser extent Fe in A2 (Ta).

Extended solubility of A2 can occur if nucleation of $\sigma$ phase is suppressed and primary solid is continuously deposited during freezing ( $\mathrm{L} \rightarrow \mathrm{A} 2$ ). The liquid and solid compositions consequently traverse the metastable extensions of the liquidus and solidus surfaces respectively. The nucleation of the peritectic phase can be suppressed if significant crystallographic mis-match exists between the two phases; in this case disordered bcc (A2) and the tetragonal, $\sigma$ phase [22]. However, this argument is not consistent with microstructural observations. The solubility limits for $\mathrm{Al}$ and Fe within A2 (S2, S1, and $\mathrm{S} 3$ ) is up to 9 at. \% for $\mathrm{Al}$ and 4 at. \% for $\mathrm{Fe}$ in the solidus projection. Therefore, solute concentrations traversing the metastable solidus should exhibit a concentration gradient within primary A2, since backdiffusion is not sufficient to eliminate these solute gradients entirely.

However this is contrary to observations, where a negligible concentration gradient was observed within the primary A2. Moreover, there is also a marked decrease in the solubility of both Al and Fe in A2 at lower temperatures and therefore extended solubility of $\mathrm{Al}$ and Fe cannot be accounted for by changing solute solubility during cooling below the solidus. On the other hand with increasing Al concentration, even though an extended solubility of Al exists within A2, nucleation and growth of $\sigma$ phase occurs via the peritectic reaction [Fig. 5(a), 5(b)], as in S4. Since there is a negligible composition gradient within the primary A2 phase in S4 and following the approach in [23], a tie-line can be drawn by joining the 
nominal alloy composition and the solid composition in the liquidus projection. This extended line intersects the A2 - $\sigma$ peritectic valley [Fig. 5(d)] and consistently explains the occurrence of the peritectic reaction.

It can be concluded that the reason for the absence of the peritectic reaction in S1, S2 and S3 must be attributed to primary freezing and therefore related to the extended solubility of $\mathrm{Al}$ and $\mathrm{Fe}$ in the primary phase. Following a similar approach as in S4, a tie-line can also be drawn by joining the nominal alloy composition and the solid composition in the liquidus projection in the case of S1, S2 and S3. The two points are pertinent to this respect;

(a) The extended line intersects the A2 - $\sigma$ peritectic valley. Therefore, if the $\mathrm{L} \rightarrow \mathrm{A} 2+\mu$ reaction was to occur following primary freezing of A2, this extended line should have intersected the A2 - $\mu$ eutectic valley instead.

(b) From the solidus projection, in the case of S2 and S3 the composition of $\mu$ phase lies adjacent to the vertex of the tie-triangle corresponding to the 4-phase invariant reaction involving $\mu$ phase. Indeed when the eutectic reaction occurs, the composition of $\mu$ phase should lie beneath this vertex along the single-phase boundary.

From (a) and (b) it can be therefore concluded that the eutectic reaction can only be rationalised if there is a "north-west" (upwards and leftwards) translation of; (i) the A2 - $\sigma$ peritectic and A2 - $\mu$ eutectic valleys in the liquidus projection and (ii) also of the vertex corresponding to $\mu$ phase corresponding to the 4-phase invariant reaction, $\mathrm{L}+\sigma \rightarrow \mathrm{A} 2+\mu$ in the solidus projection. This north-west shift in peritectic and eutectic valleys coupled with the extended solubility of $\mathrm{Al}$ and $\mathrm{Fe}$ in $\mathrm{A} 2$ is a clear manifestation of a decrease in solute partitioning during primary freezing. This is a clear manifestation of the loss of interfacial equilibrium during primary solidification.

The loss of interfacial equilibrium arises during freezing at very high cooling rates, where $\delta$ (characteristic distance) $<<D_{L} / V$, where " $V$ " is the interface migration rate and $D_{L}$ is the solute diffusivity at the interface [24]. Qualitatively, this phenomenon can be understood in relation to the arc melting process as follows - when the copper-cooled hearth is maintained at a fixed temperature $\left(\sim 100^{\circ} \mathrm{C}\right)$, a higher melt superheat will result in a high thermal gradient and therefore increased cooling rates during the initial stages of solidification $\sim 10 \mathrm{~mm}$ (diameter of bar). From an examination of the liquidus projection [10], the liquidus temperature for the different alloys can be approximately ascertained. When the primary phase was $\mathrm{A} 2$, the liquidus temperatures were in the range $[2400-2600]^{\circ} \mathrm{C}$, while when $\sigma$ was the primary phase, liquidus temperatures were in the range $[1800-1900]^{\circ} \mathrm{C}$. It is clear that the increased superheat, $\sim 600^{\circ} \mathrm{C}$ can qualitatively account for greater cooling rates for the compositions with higher liquidus temperature. Specifically in the case of S4, the composition of $\sigma$ phase almost lies 
on the boundary of the solidus projection, with no extended solubility and which is consistent with this argument.

A definitive confirmation of these effects during primary freezing of $\mathrm{A} 2$ is obtained from the splat cooling experiments. Two representative cases were considered,

(a) S5 - The extended line joining the A2 composition and nominal composition intersects the A2 - $\mu$ eutectic valley. Not only is there an extended solubility of $\mathrm{Al}$ and $\mathrm{Fe}$ in $\mathrm{A} 2$, but also the composition of $\mu$ phase shows extended solubility of Ta.

(b) S6 - The extended line joining the A2 composition and nominal composition intersects the A2 - $\sigma$ peritectic valley. Not only is there an extended solubility of Al and Fe in A2, but also the composition of $\mu$ phase shows extended solubility of Ta and Al.

(c) It must be noted that the changing solute composition during cooling within $\mu$ phase cannot account for extended solute solubility, since the $\mathrm{A} 2+\mu / \mu$ phase boundary shifts towards higher $\mathrm{Fe}$; contrary to the measured composition. Therefore, increasing the cooling rate through splat quenching additionally leads to non-equilibrium freezing during $\mathrm{L} \rightarrow \mathrm{A} 2+\mu$, with trapping of Ta and Al within $\mu$ phase.

There is a range of solid compositions that can form from the liquid under non-equilibrium conditions provided $\Delta \mathrm{G}=\left[\mathrm{G}_{\mathrm{S}}-\mathrm{G}_{\mathrm{L}}\right]<0$, per mole of solid. Extrapolating from the binary phase diagram to the ternary case [24];

$$
\begin{aligned}
& \frac{\Delta \mathrm{G}}{\mathrm{RT}}=\left(1-\mathrm{k}_{\mathrm{B}}\right)\left[1+\left(\frac{\mathrm{k}_{\mathrm{B}}-\mathrm{k}_{\mathrm{B}}^{\mathrm{v}}\left(1-\ln \left(\frac{\mathrm{k}_{\mathrm{B}}^{\mathrm{V}}}{\mathrm{k}_{\mathrm{B}}}\right)\right)}{1-\mathrm{k}_{\mathrm{B}}}\right)\right] \mathrm{X}_{\mathrm{L}}^{\mathrm{B}}-\left(1-\mathrm{k}_{\mathrm{B}}\right) \mathrm{X}_{\mathrm{L}}^{\mathrm{B}, \mathrm{e}}+\left(1-\mathrm{k}_{\mathrm{C}}\right)[1+ \\
& \left.\left.\left(\frac{\mathrm{k}_{\mathrm{C}}-\mathrm{k}_{\mathrm{C}}^{\mathrm{v}}\left(1-\ln \left(\frac{\mathrm{k}_{\mathrm{C}}^{\mathrm{v}}}{\mathrm{k}_{\mathrm{C}}}\right)\right)}{1-\mathrm{k}_{\mathrm{C}}}\right)\right] \mathrm{X}_{\mathrm{L}}^{\mathrm{C}}-\left(1-\mathrm{k}_{\mathrm{B}}\right) \mathrm{X}_{\mathrm{L}}^{\mathrm{C}, \mathrm{e}}\right]
\end{aligned}
$$

where, $k_{B}$ and $k_{C}$ are the equilibrium partition coefficients for solutes $\mathrm{B}$ and $\mathrm{C}$ respectively, while the superscript "v" refers to those values under non-equilibrium conditions. The superscript "e" refers to equilibrium interfacial concentrations. In metallic systems interfacial attachment kinetics are infinitely rapid and therefore all of $\Delta G$ is consumed for migration of the interface from solute trapping effects [25 - 27]. However unlike in the binary phase diagram, where "partition coefficient ( $k$ )" is fixed at a given temperature during primary freezing, this is not the case in ternary systems, since an added degree of freedom exists and therefore $X_{L}$ and $X_{S}$ and therefore " $k$ " for solutes B and $\mathrm{C}$ are determined by kinetic considerations as;

$$
\left[X_{L}^{* B}-X_{S}^{* B}\right] d f_{S}=\int D_{S} \frac{d X_{S}^{B}}{d x} d t+\left(1-f_{S}\right) d X_{L}^{B}
$$




$$
\left[X_{L}^{* C}-X_{S}^{* C}\right] d f_{S}=\int D_{S} \frac{d X_{S}^{C}}{d x} d t+\left(1-f_{S}\right) d X_{L}^{C}
$$

where, the new solute composition in the liquid at $[\mathrm{T}-\Delta \mathrm{T}]$ is given by,

$$
\begin{aligned}
& X_{L}^{B}=\left[X_{L}^{* B}+d X_{L}^{B}\right] \\
& X_{L}^{C}=\left[X_{L}^{* C}+d X_{L}^{C}\right]
\end{aligned}
$$

from which " $k$ " at $[\mathrm{T}-\Delta \mathrm{T}]$ is given by, $\mathrm{k}^{\mathrm{i}}=\frac{\mathrm{X}_{S}^{\mathrm{i}}}{\mathrm{x}_{\mathrm{L}}^{\mathrm{i}}}$.

Such calculations are therefore not straightforward in ternary systems. Notwithstanding this, the range of solid compositions within A2 and $\mu$ phase are plotted in Fig. 5. It is clear that a markedly extended solubility of $\mathrm{Al}$ and $\mathrm{Fe}$ exists that significantly exceeds the boundaries of the solidus projection, during primary freezing of A2.

The eutectic morphology in S2 and S3 also merits some attention. While the initial $[\mathrm{A} 2+\mu]$ morphology is divorced, a distinct lamellar morphology is observed within $\mu$ phase remote from the primary dendrite lobes. At the end of primary freezing, nucleation of $\mu$ phase will occur on the dendrite lobes and not within the bulk liquid. During eutectic freezing growth of both A2 and $\mu$ phase occurs independent of each other, as primary growth, $\mathrm{L} \rightarrow \mathrm{A} 2$ and $\mathrm{L} \rightarrow \mu$. However, if $\mu$ phase completely grows around the primary solid, A2, then further eutectic growth necessarily requires nucleation of A2. This is the most likely reason for the lamellar morphology observed within $\mu$ phase in the inter-dendritic region. Moreover, as the lamellar morphology is located in the middle of the inter-dendritic region, it is formed in the terminal stages of solidification and hence consistent with the above explanation. An exact analogous situation is observed in the case of S4, where following the peritectic reaction a rim of $\sigma$ phase forms around A2 and subsequently isolates A2 from the liquid [Fig. 5(b)]. The subsequent peritectic transformation involving solid-state diffusion through $\sigma$ phase is therefore restricted. This results in the primary growth of $\sigma$ phase, $L \rightarrow \sigma$, where the liquid composition traverses the $\sigma$ liquidus before intersecting the $\sigma-\mu$ eutectic valley and resulting in the eutectic reaction, $L \rightarrow \sigma+\mu$.

It should be noted that so far the analysis has been based on the principle of the loss of equilibrium at the interface. No consideration has been given to the bulk phases and this aspect will be considered now in some brevity. It is well known that intermediate or metastable phases can nucleate within the supercooled liquid. This can arise either from;

- Molecular re-arrangements allowing stabilisation of new phases from increase in entropy instead of minimisation of internal energy [28] or, 
- The metastable phase has the larger molar driving force compared with the equilibrium phase [29].

The latter becomes particularly relevant, e.g. in the initial stages of precipitation [30] or when there is a marked variation in the crystal structure of the parent and daughter phase resulting in larger interfacial energies. This activation energy has to be then overcome by a larger molar driving force or by coarsening via Ostwald ripening [31]. The nucleation and growth of a metastable phase will result in a difference in the solute solubility of the primary A2 phase, but it is not clear if it would result in an extended solubility. However, two factors militate against the proposition of the nucleation of a metastable phase;

(a) The occurrence of the eutectic reaction, involving A2 $+\mu$ phases, where clearly the "precursor" $\mu$ phase is not metastable, but only arises from the path traversed by the liquid composition on the A2 liquidus surface.

(b) The occurrence of the peritectic reaction for higher $\mathrm{Al}$ and lower Fe content resulting in $\sigma$ phase (equilibrium phase), which precludes the eutectic reaction (i.e. $\mu$ phase).

From (a) and (b) it can therefore be unequivocally confirmed that the deviation in the solidification path only arises from loss in interfacial equilibrium and not from loss of equilibrium in the bulk phases through nucleation of a metastable phase.

\section{Conclusions}

The reaction sequence of Ta-Al-Fe system in the Ta-rich corner under rapid solidification condition was investigated with the following conclusions,

(1) Primary solidification of A2 (Ta) is accompanied by loss of interfacial equilibrium resulting in extended solubility of primarily $\mathrm{Al}$ and to a lower extent $\mathrm{Fe}$ in $\mathrm{A} 2$ for samples made via arc melting.

(2) Non-equilibrium solidification leads to deviation of the solidification path from that predicted by equilibrium liquid and solidus projections following primary freezing.

(3) For less than 10 at. $\% \mathrm{Al}$ and less than 4 at. $\% \mathrm{Fe}$, the peritectic reaction, $\mathrm{L}+\mathrm{A} 2 \rightarrow \sigma$ is suppressed and instead the eutectic reaction, $\mathrm{L} \rightarrow \mathrm{A} 2+\mu$ was observed following primary freezing, $\mathrm{L} \rightarrow \mathrm{A} 2$. Extended solubility of $\mathrm{Al}$ within $\mathrm{A} 2$ up to 15 at. \% was observed even when the peritectic reaction occurred.

(4) Non-equilibrium freezing occurs because of increased cooling rates that arose from higher melt superheat for alloys with higher liquidus temperature. Additionally under splat cooling conditions, non-equilibrium freezing was exhibited not only during primary freezing, but also during the $\mathrm{A} 2+\mu$ eutectic reaction. 


\section{Acknowledgements}

One of the authors (ND) would wish to acknowledge funding from the Accelerated Metallurgy Project, which is co-funded by the European Commission in the $7^{\text {th }}$ Framework Programme (Contract NMP4LA-2011-263206) and by the individual partner organisations. LMF would wish to thank CNPq for funding $\mathrm{PhD}$ study.

\section{References}

[1] R. C. Reed, Superalloys: Fundamentals and Applications, Cambridge University Press, Cambridge, 2006.

[2] D. Welton, N. D'Souza, J. Kelleher, S. Gardner, Z.H. Dong, G. D. West, H.B. Dong, Metall. Mater. Trans A. 46 (2015), 4298-4315.

[3] N. D'Souza, S. Simmonds, H.B. Dong, G.D. West, Metall. Mater. Trans A. 44 (2013), 47644773 .

[4] G. Brewster, N. D'Souza, K. Ryder, S. Simmonds, H. B. Dong, Metall. Mater. Trans A 43 (2012), 1288-1302.

[5] H.J. Dai, N. D’Souza, H. B. Dong, Metall. Mater. Trans A, 42, (2011), 3430-3438.

[6] Beardmore et al, Trans. of Metal. Soc. AIME, 1979, Vol. 245, pp. 1537 -

[7] Polvaniet al, Met. Trans. A, 1976, Vol. 7, pp. 33 - 40.

[8] P. Cerba, M. Vilasi, B. Malaman, J. Steinmetz, J. Alloys and Compounds, 1993, Vol. 201, pp. $57-60$.

[9] G. Ghosh, G. B. Olson, Acta Mater., 2007, Vol. 55, pp. 3281 - 3303.

[10] V. T. Witusiewiczet al, J. Mat. Sci., 2013, Vol. 48, pp. 377 - 412.

[11] G. Ghosh, In G. Effenberg, S. Illyenko (eds) Landolt - Bornstein numerical data and functional relationships in materials science and technology, Group IV, W. Martinsen (ed) Physical chemistry, ternary alloy systems, Phase diagrams, crystallographic and thermodynamic data critically evaluated by MSIT, Vol. 11D1, Springer Berlin, 2008, p. 213.

[12] K. S. Kumar, Int. Mater. Rev., 1990, Vol. 35, pp. 293 - .

[13] V. Raghavan, Phase Diagrams of Ternary Iron Alloys, Part 6A, Indian Inst. of Met., Calcutta, 1992, p. 187.

[14] C. R. Hunt, A. Raman, Z. Metallkde, 1968, vol. 59, pp. 701 - 707. 
[15] E.C. Kurum, H.B. Dong, J.D. Hunt, Metall. Mater. Trans A., 36 (2005), 3103-3110.

[16] W. J. Boettinger, U. R. Kattner, D. K. Banerjee, Modelling and Casting of Advanced Solidification Processes (MCWASP), VIII, Eds. B. G. Thomas, C. Beckermann, TMS, 1998, pp. $159-170$.

[17] Y. Ruan, W. J. Xie, Intermetallics, 2012, Vol. 31, pp. 232 - 241.

[18] WL. Wang, FP. Dai, B. Wei, Sci. in China Series G, Phys. Mech., Astronomy, 2007, Vol. 50, pp. $472-490$.

[19] N. D’Souza, H.B. Dong, Script Materialia, 56 (2007): 41-44.

[20] H. W. Kerr, W. Kurz, Int. Mater. Rev., 1996, Vol. 41, pp. 129 - 164.

[21] M. Hillert, in "Solidification and Casting of Metals", 1979, The Metals Soc., London, pp. 81 87.

[22] S. Hashimoto, K. F. Kobayashi, S. Miura, Z. Metallkd., 1983, Vol. 74, pp. 787 - 792.

[23] D. R. F. West, N. Saunders, “Ternary Phase Diagrams in Materials Science”, 2002, $3^{\text {rd }}$ ed., Maney, Inst. of. Met., pp. $67-68$.

[24] W. Kurz, D. J. Fisher, "Fundamentals of Solidification", 1986, Vol. 1, Trans. Tech Publ., pp. $134-136$ and pp. $221-224$.

[25] H. Assadi, A. L. Greer, J. Cryst. Growth, 1997, Vol. 172, pp. 249 - 258.

[26] S. B. Sobolev, Phy. Lett. A, 1995, Vol. 199, pp. 383 - 386.

[27] S. B. Sobolev, Phy. Rev. E, 1997, Vol. 55, pp. 6845 - 6854.

[28] A. Sanz, A. Nogales, I. Puente-Orench, M. Jimenez-Ruiz, T. A. Ezquerra, Phy. Rev. Lett. 2011, Vol. 107, pp. 025502-1 - 025502-4.

[29] J. C. Baker, J. W. Cahn, "Solidification", 1971, ASM International, OH, 1971, pp. 23 - 58.

[30] M. Hillert, "Lectures on the Theory of Phase Transformations", 1975, Ed. H. I. Aaronson, pp. $24-27$.

[31] F. Shi, Y. Shim, J. G. Amar, Phy. Rev. E, 2007, Vol. 76, pp. 031607-1 - 031607-8. 


\section{List of Figures}

Fig. 1 Alloy compositions plotted on the Gibbs triangle corresponding to, (a) liquidus projection, (b) solidus projection [after reference 10].

Fig. 2 Back-scattered electron images corresponding to S1, (a) low magnification, (b) high magnification; measured composition in solid phases plotted (c) on liquidus and (d) on solidus projections Also included are phase boundaries with decreasing temperature.

Fig. 3 Back-scattered electron images corresponding to S2, (a) low magnification, (b) high magnification; measured composition in solid phases plotted (c) on liquidus and (d) on solidus projections Also included are phase boundaries with decreasing temperature.

Fig. 4 Back-scattered electron images corresponding to S3, (a) low magnification, (b) high magnification; measured composition in solid phases plotted (c) on liquidus and (d) on solidus projections Also included are phase boundaries with decreasing temperature.

Fig. 5 Back-scattered electron images corresponding to S4, (a) low magnification, (b) high magnification; measured composition in solid phases plotted (c) on liquidus and (d) on solidus projections Also included are phase boundaries with decreasing temperature.

Fig. 6 Back-scattered electron images corresponding to S6, (a) low magnification, (b) high magnification; measured composition in solid phases plotted (c) on liquidus and (d) on solidus projections Also included are phase boundaries with decreasing temperature.

Fig. 7 Back-scattered electron images corresponding to S5, (a) low magnification, (b) high magnification; measured composition in solid phases plotted (c) on liquidus and (d) on solidus projections Also included are phase boundaries with decreasing temperature. 


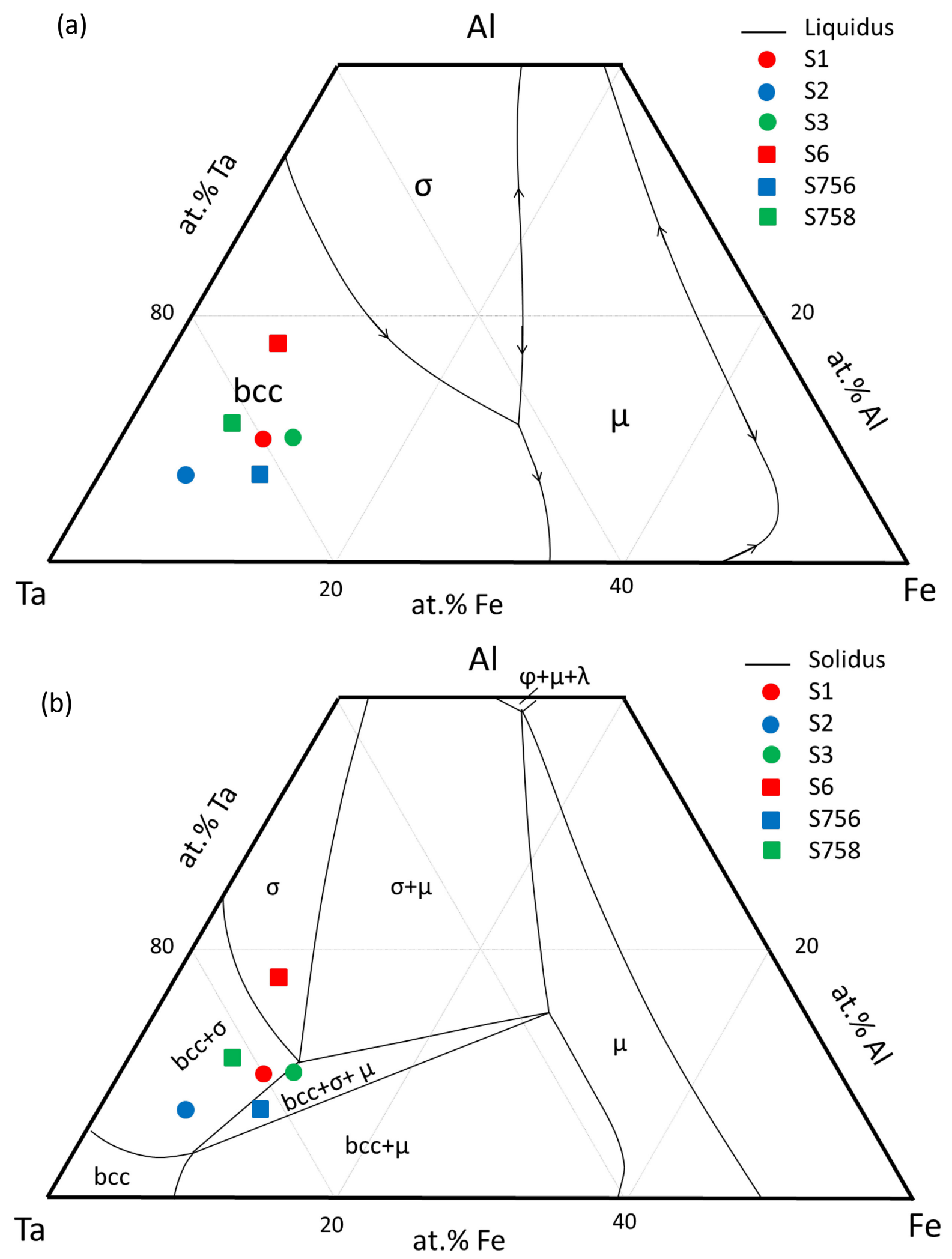

Fig. 1 Alloy compositions plotted on the Gibbs triangle corresponding to, (a) liquidus projection, (b) solidus projection [after reference 10]. 

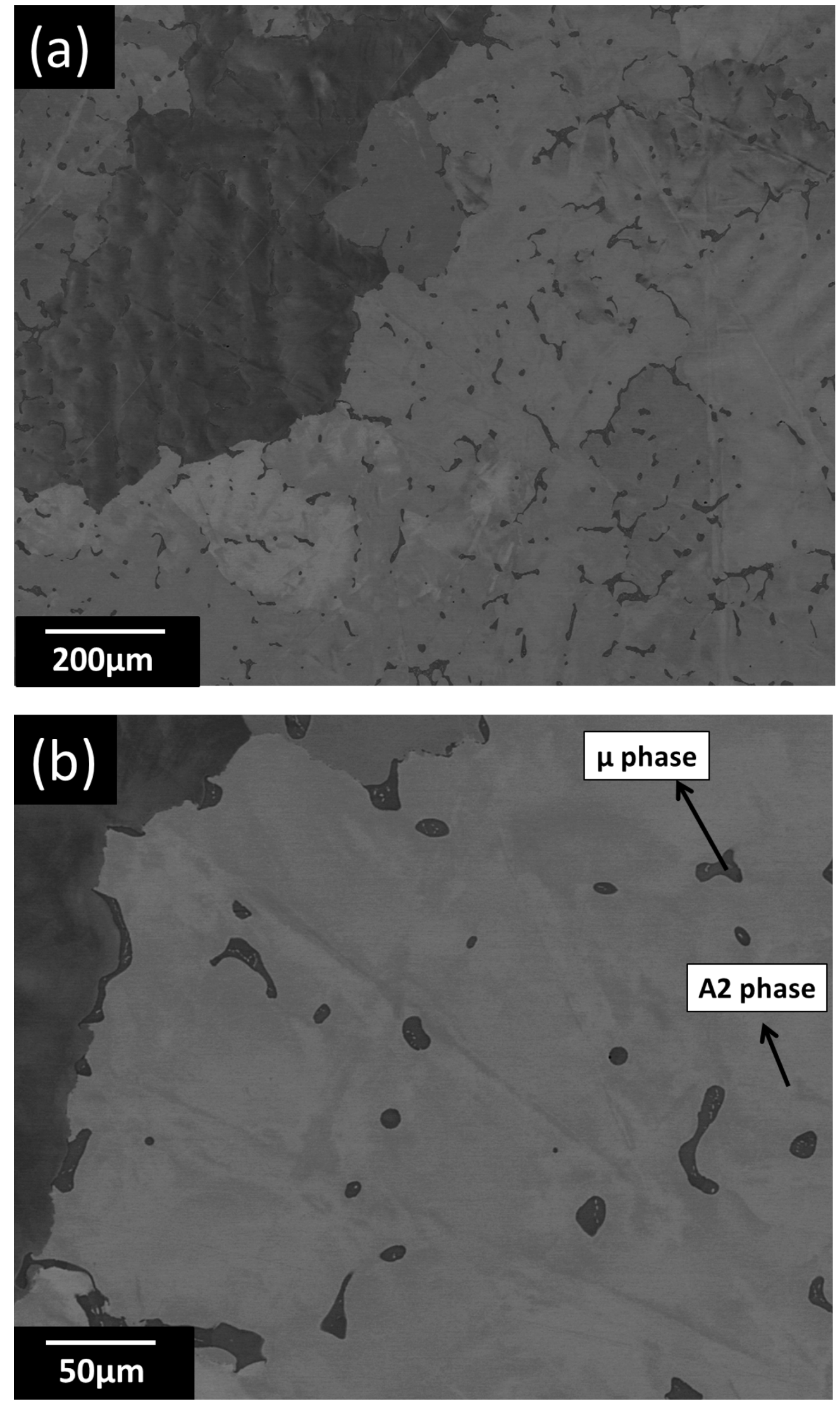

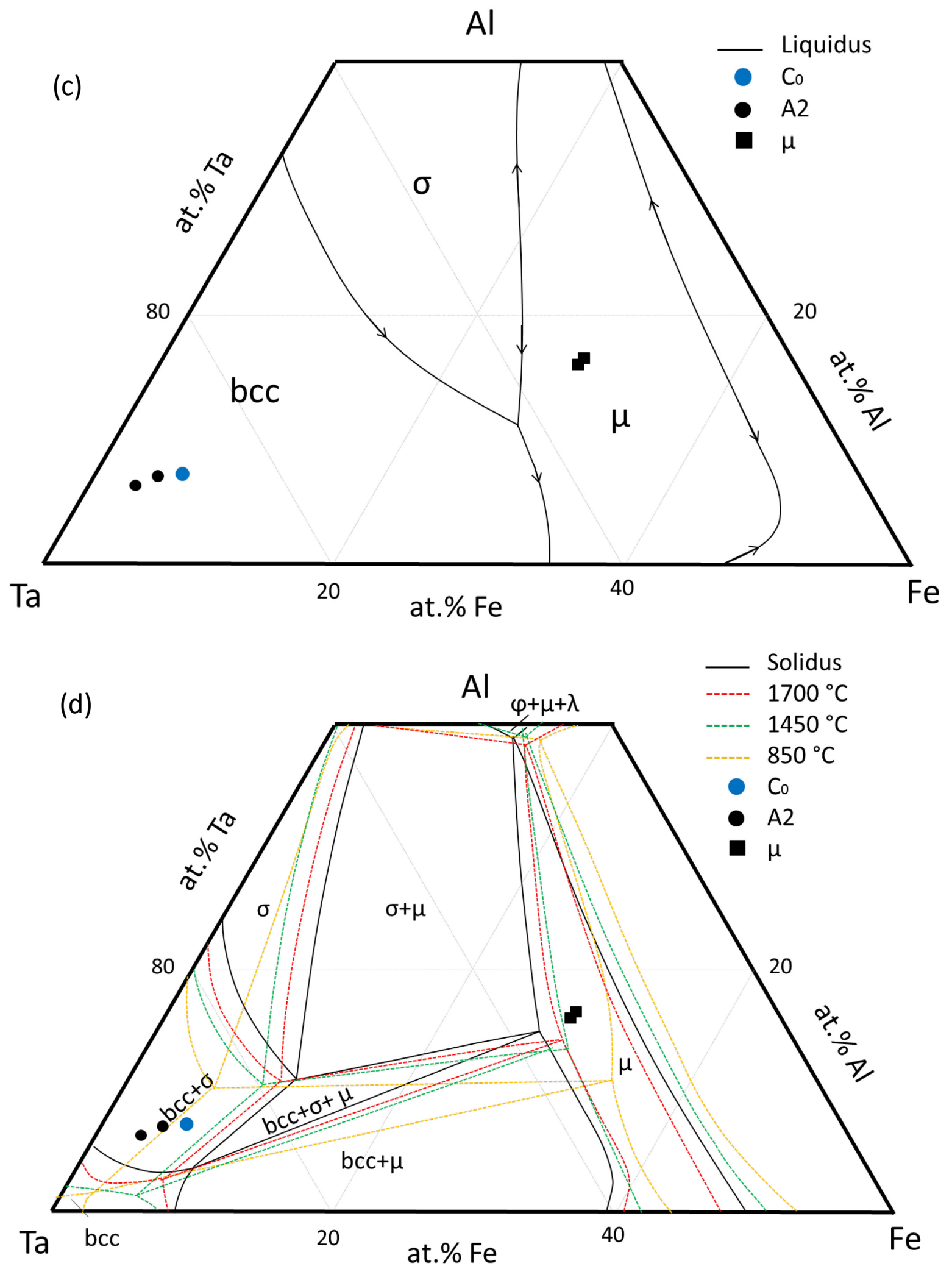

Fig. 2 Back-scattered electron images corresponding to S1, (a) low magnification, (b) high magnification; measured composition in solid phases plotted (c) on liquidus and (d) on solidus projections. Also included are phase boundaries with decreasing temperature. 

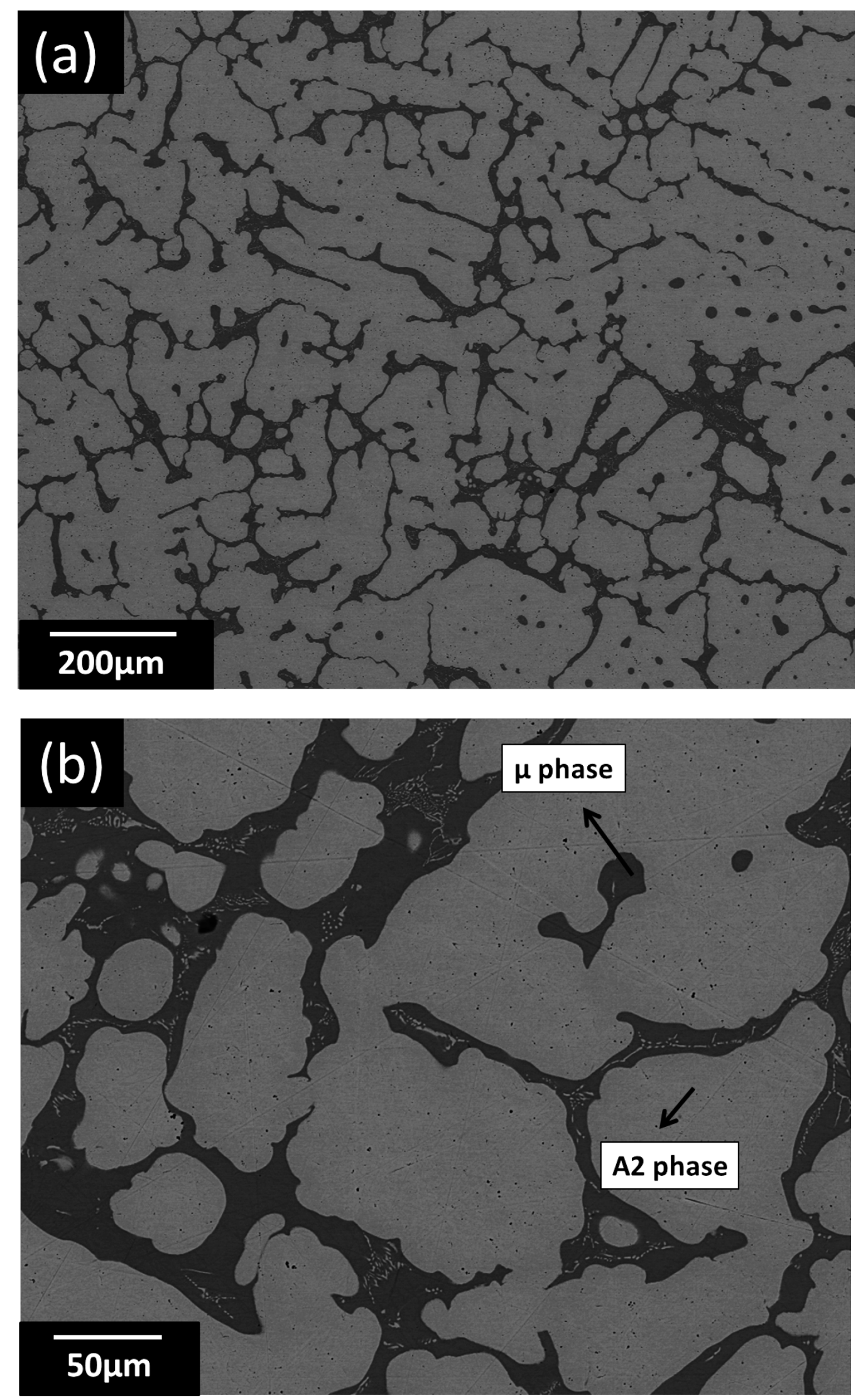

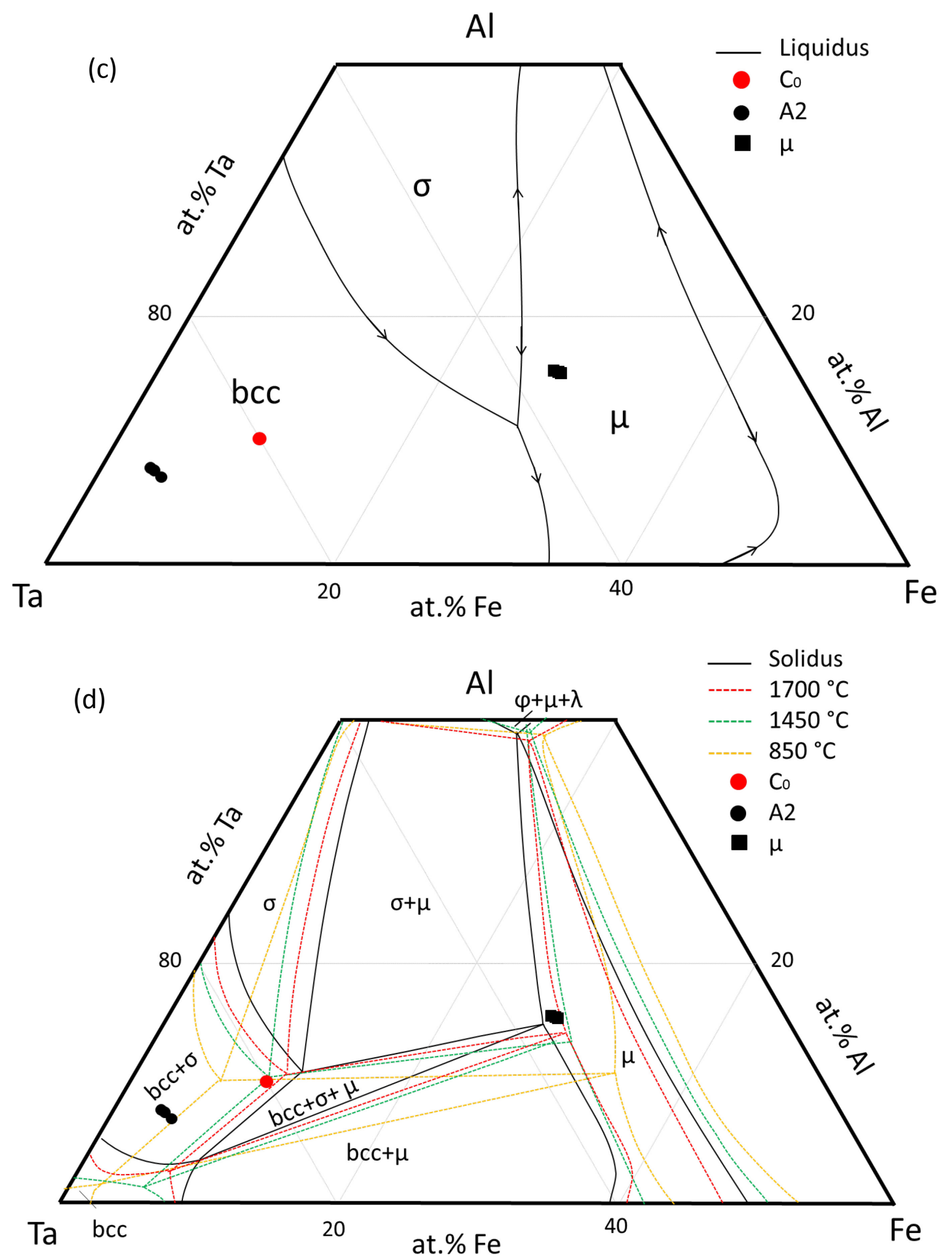

Fig. 3 Back-scattered electron images corresponding to S2, (a) low magnification, (b) high magnification; measured composition in solid phases plotted (c) on liquidus and (d) on solidus projections Also included are phase boundaries with decreasing temperature. 

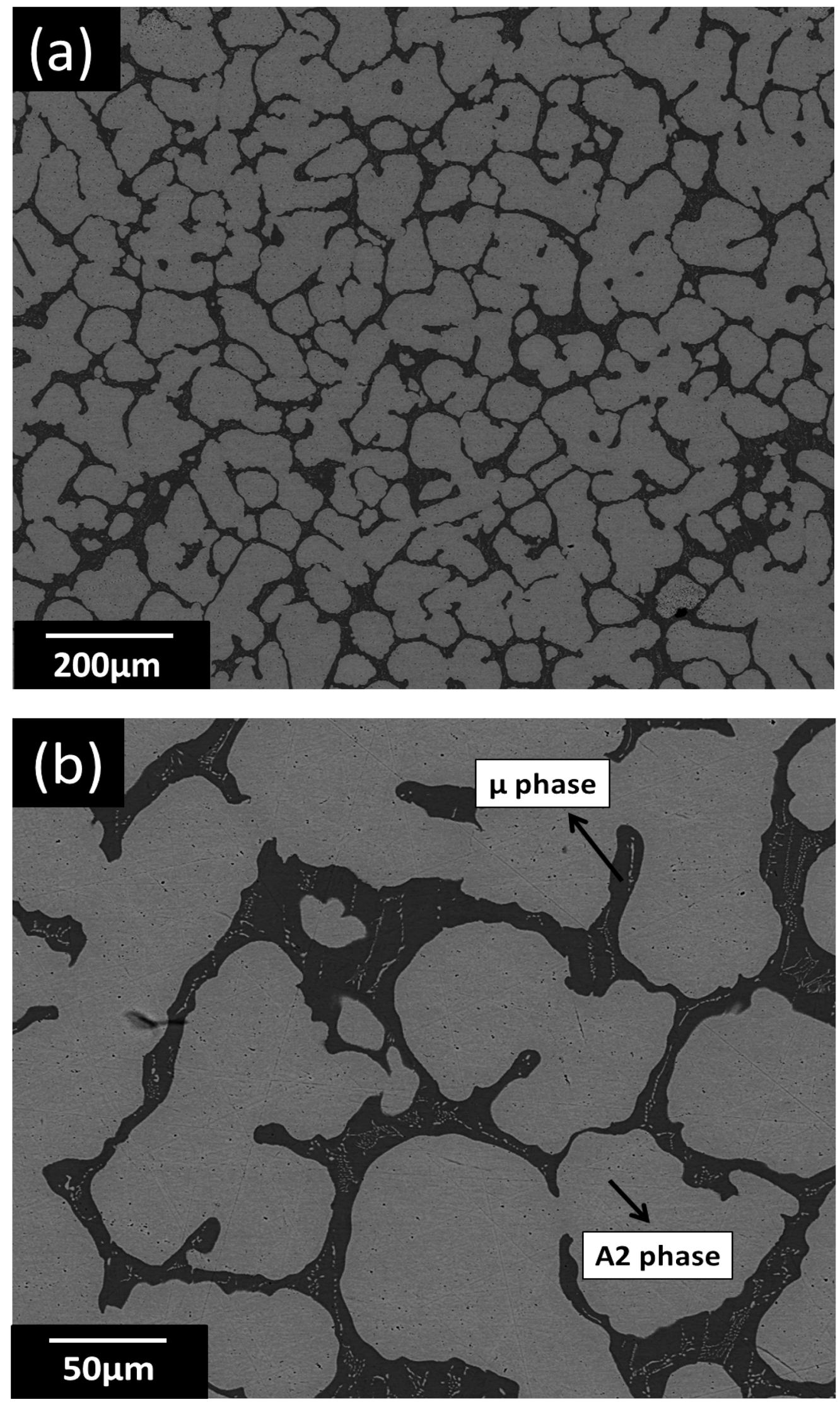

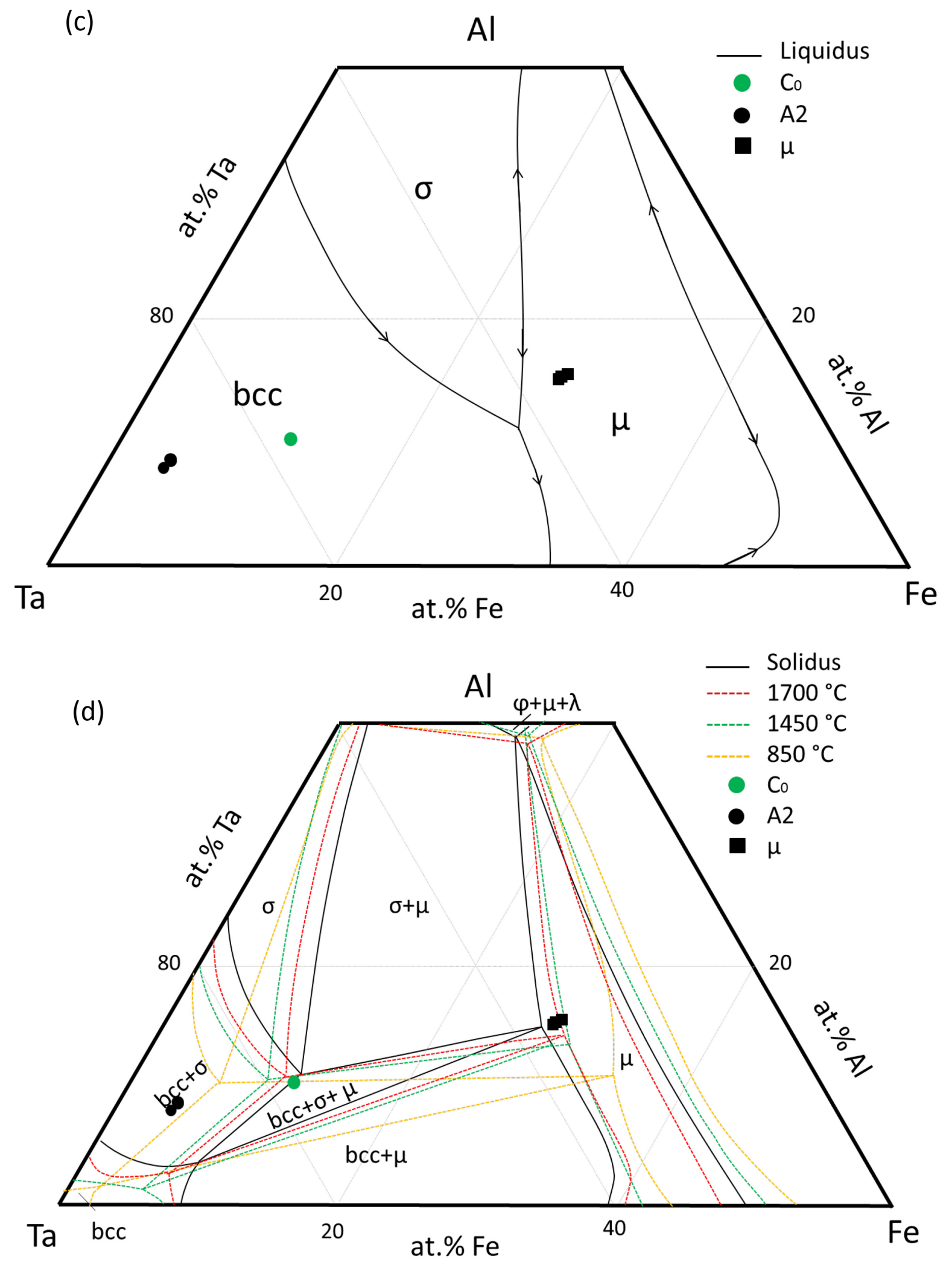

Fig. 4 Back-scattered electron images corresponding to S3, (a) low magnification, (b) high magnification; measured composition in solid phases plotted (c) on liquidus and (d) on solidus projections Also included are phase boundaries with decreasing temperature. 

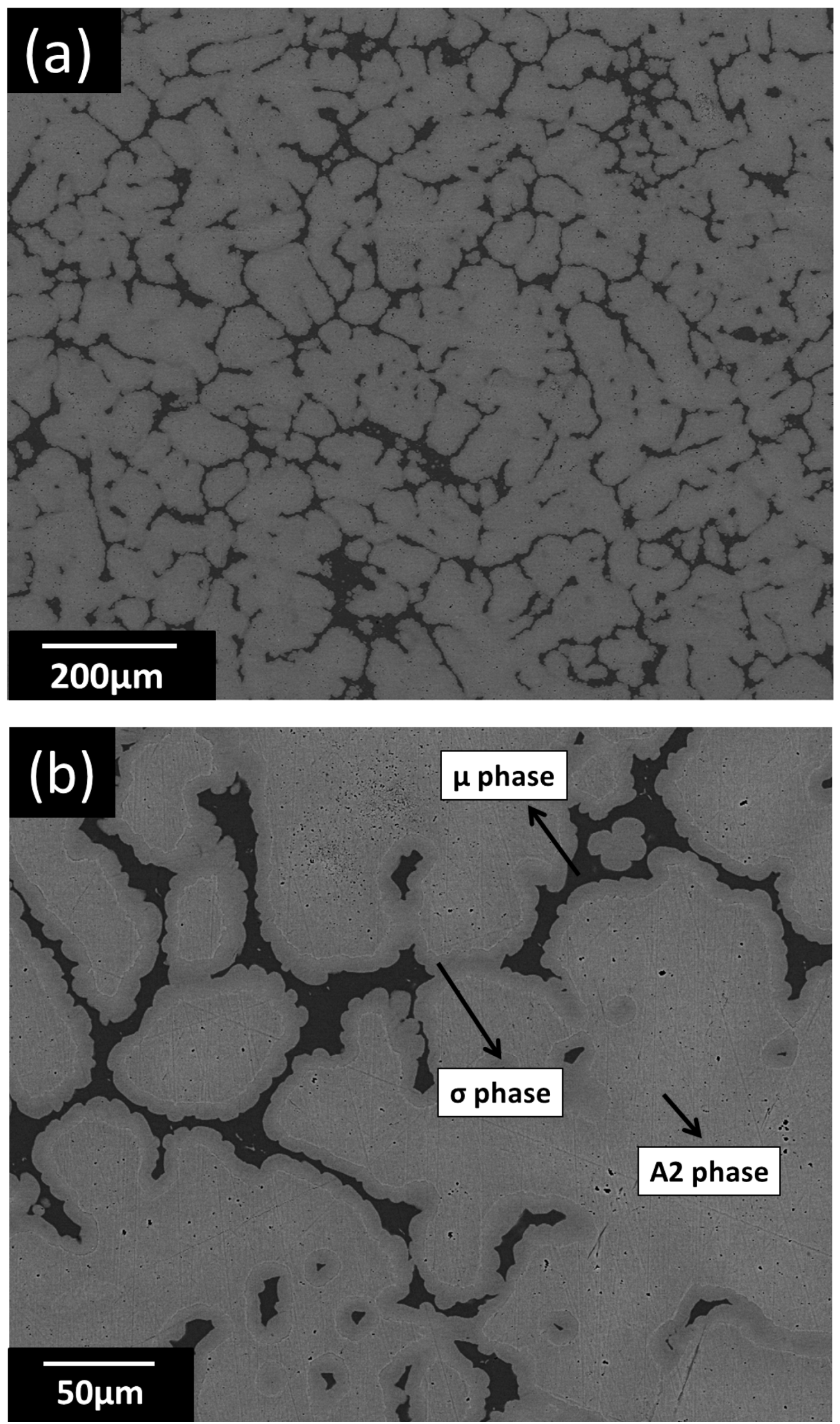

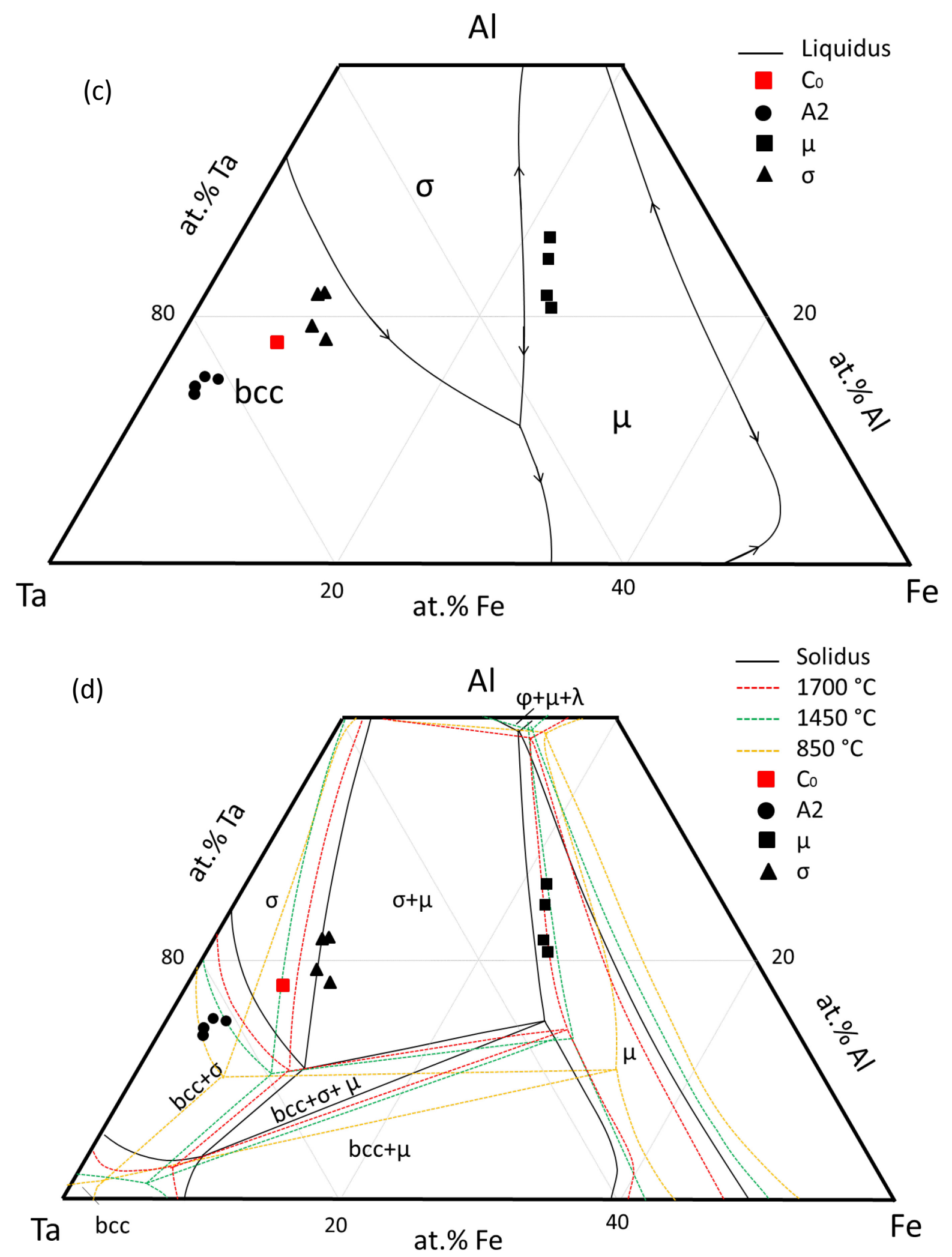

Fig. 5 Back-scattered electron images corresponding to S4, (a) low magnification, (b) high magnification; measured composition in solid phases plotted (c) on liquidus and (d) on solidus projections. Also included are phase boundaries with decreasing temperature. 

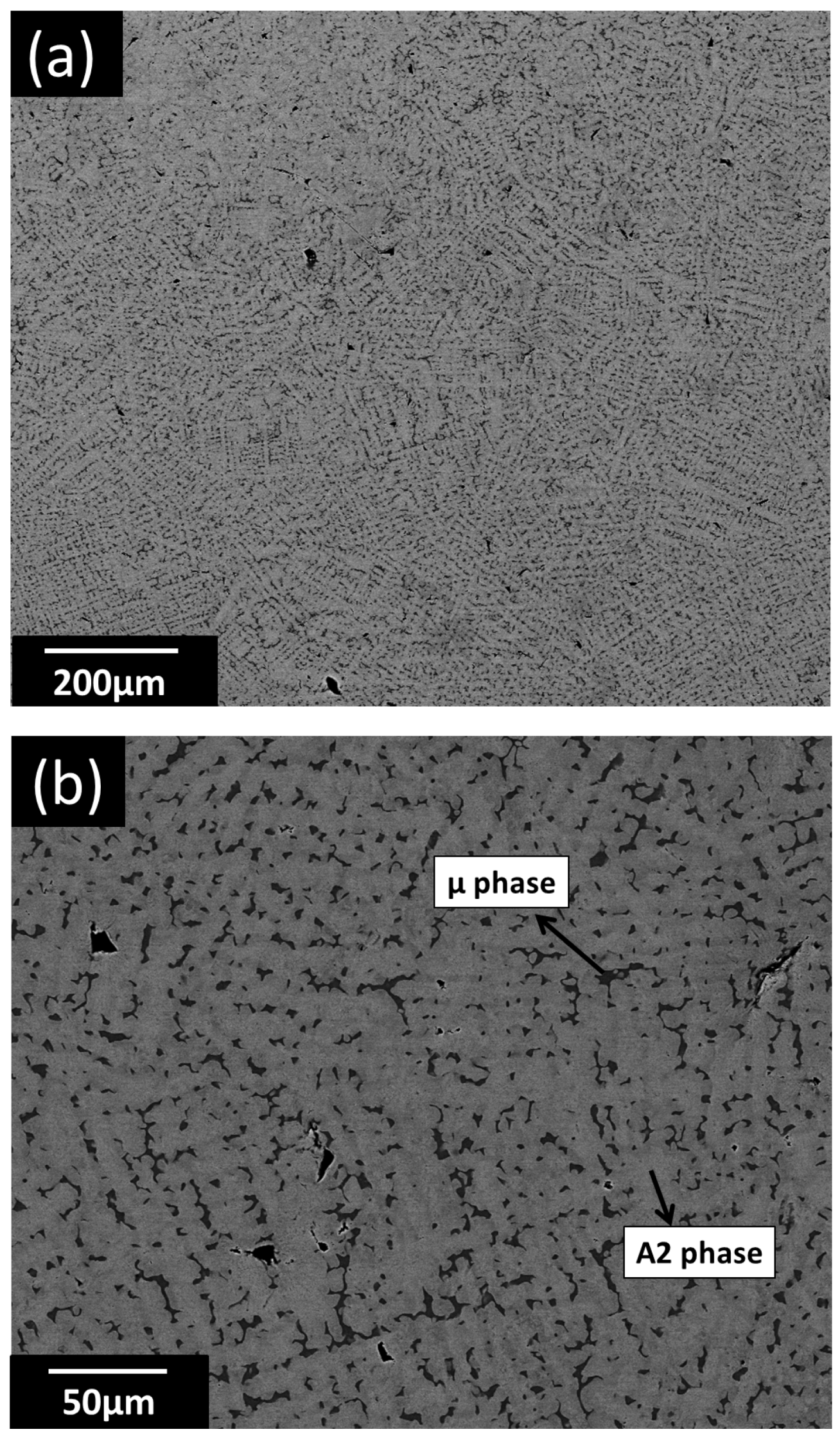


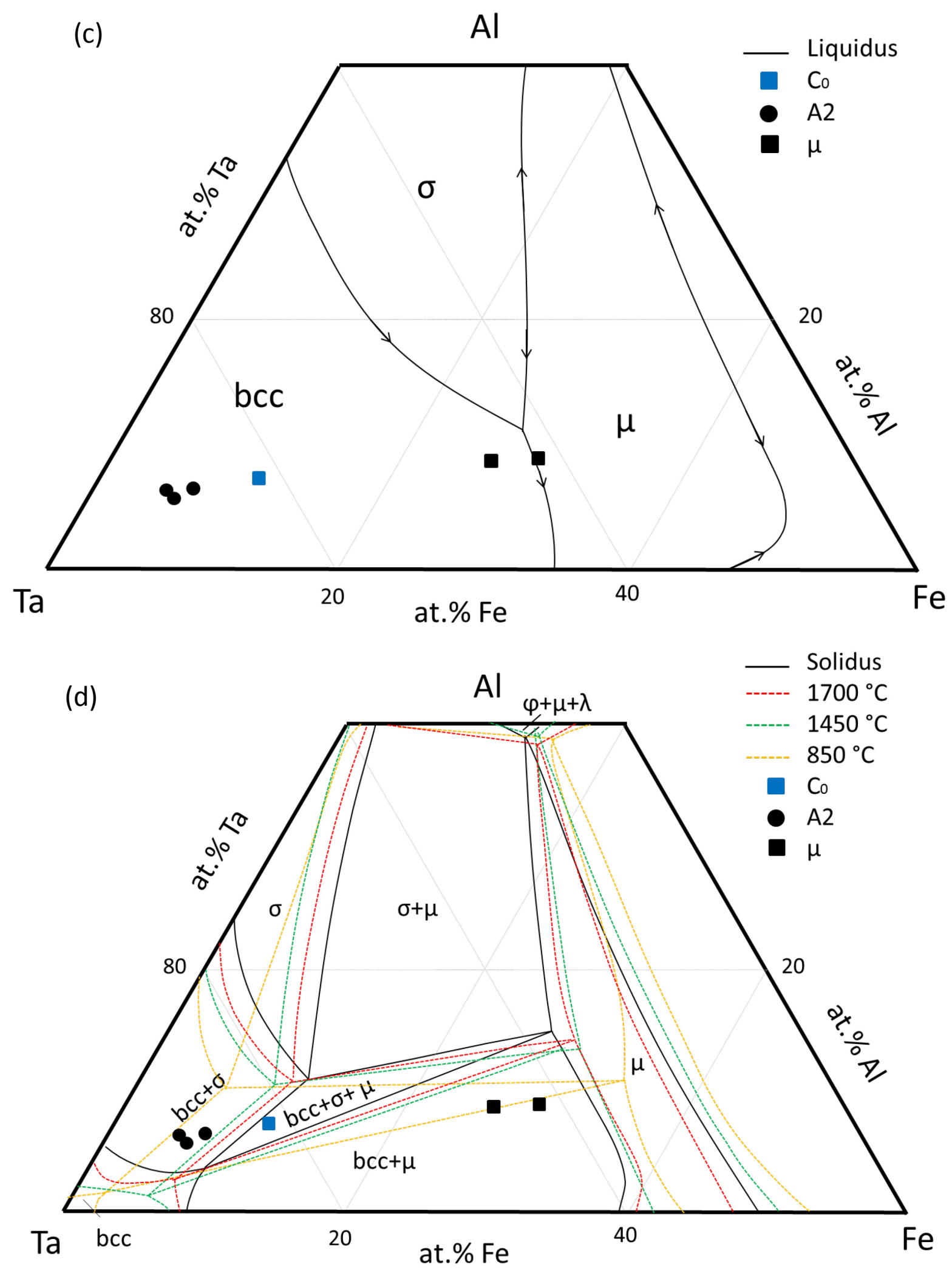

Fig. 6 Back-scattered electron images corresponding S6, (a) low magnification, (b) high magnification; measured composition in solid phases plotted (c) on liquidus and (d) on solidus projections. Also included are phase boundaries with decreasing temperature. 

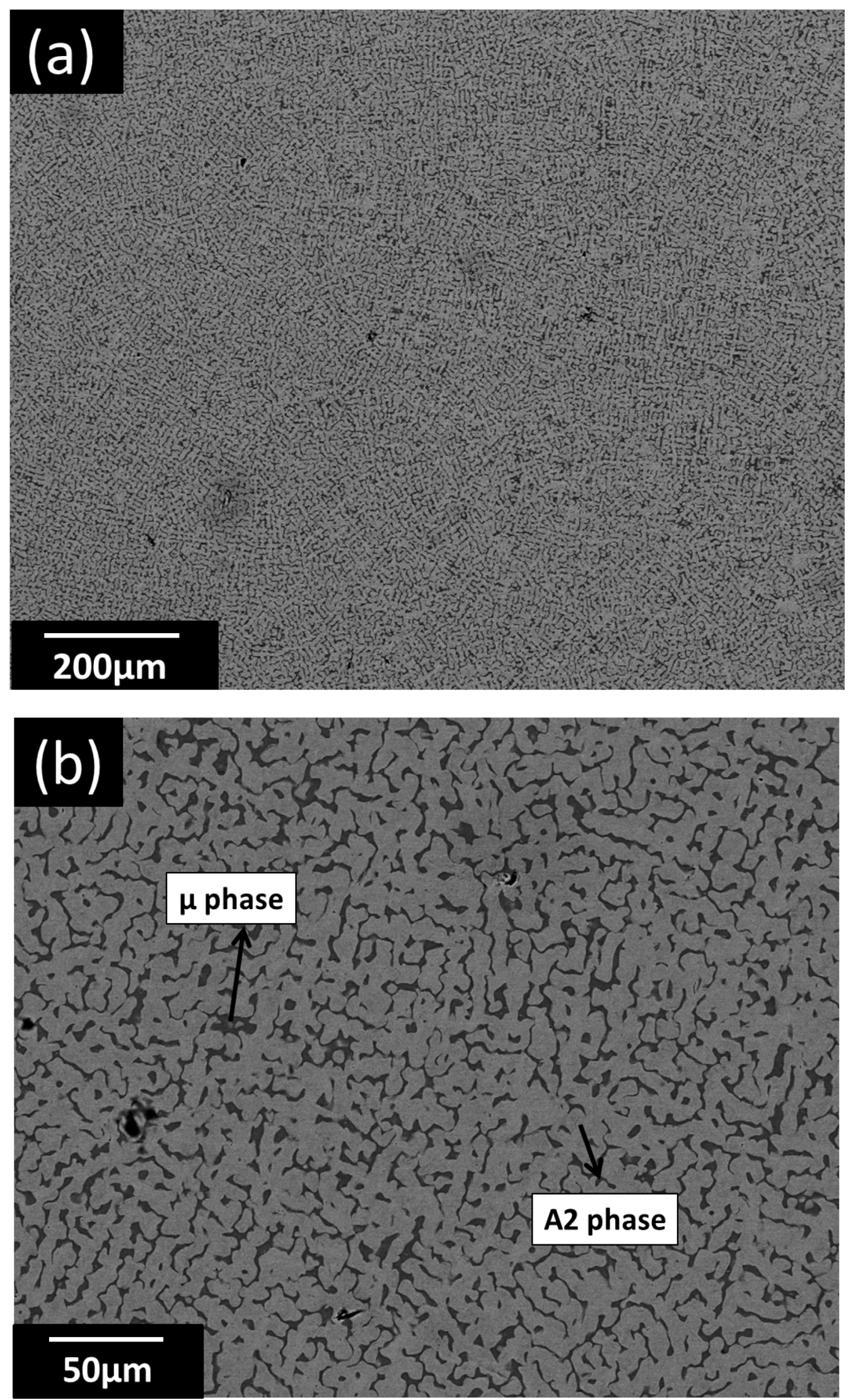

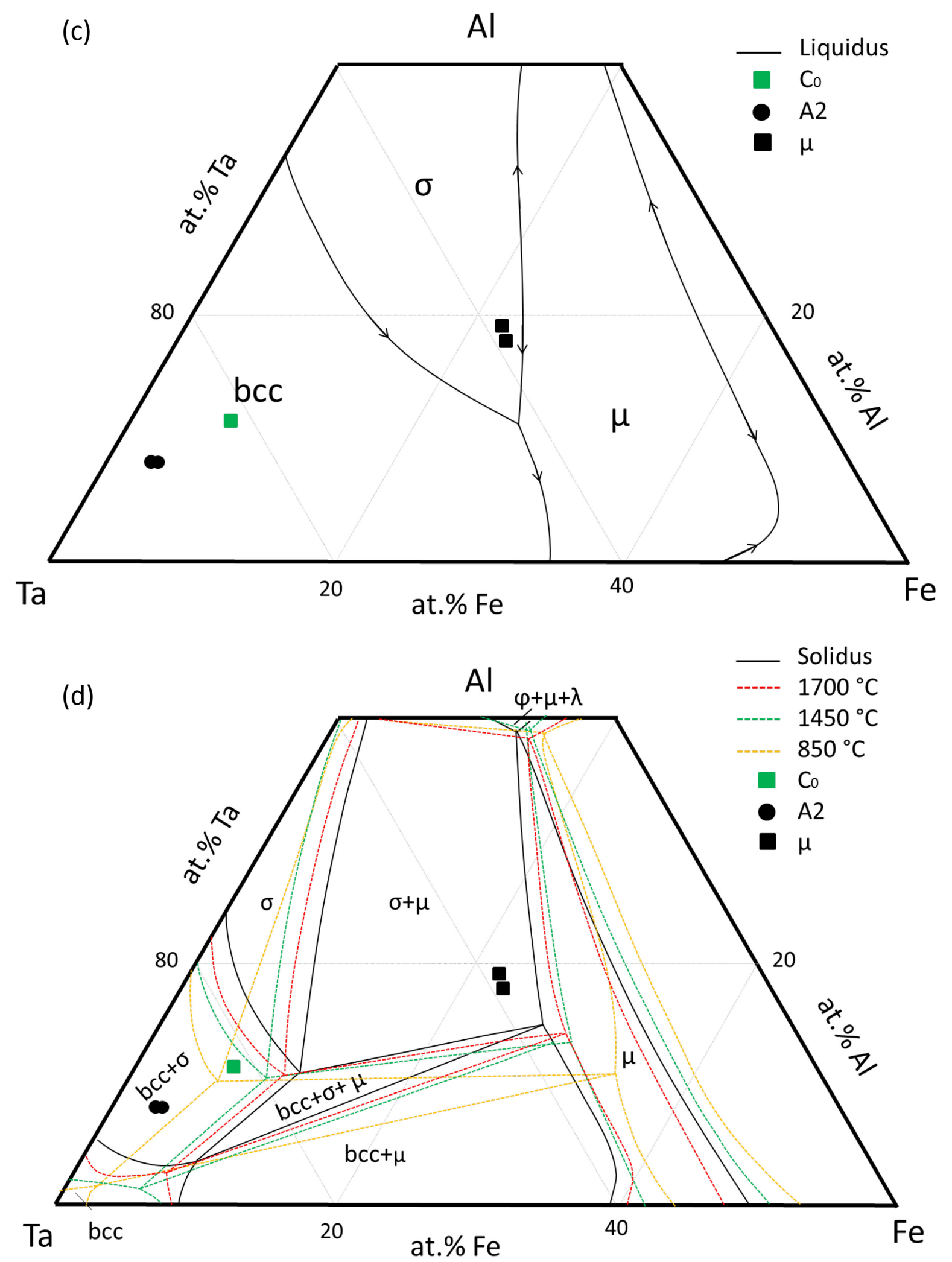

Fig. 7 Back-scattered electron images corresponding S5, (a) low magnification, (b) high magnification; measured composition in solid phases plotted (c) on liquidus and (d) on solidus projections. Also included are phase boundaries with decreasing temperature. 